Berkeley, California, USA

marajenn@gmail.com

Cite this as: BMJ 2020;371:m4115 http://dx.doi.org/10.1136/bmj.m4115 Published: 16 November 2020
HEALTHY DRY CITIES

\section{Protecting health in dry cities: from evidence to action}

Cities in the US and beyond are increasingly claiming heat readiness as the climate crisis escalates, while starting to recognize its disproportionate burden on poorer residents. But are their plans sufficient, and can they implement them fast enough? Mara Kardas-Nelson reports

\section{Mara Kardas-Nelson journalist}

Throughout July 2019 school students and volunteers meticulously mapped the outdoor air temperature across the US city of Yonkers in New York state. Although water scarcity is not a concern in the area, the 200000 residents of Yonkers are increasingly affected by heat-and some demographics more than others.

The spatial temperature data collected were then compared with maps showing tree density and surface materials, such as concrete and asphalt. These factors help to create the "urban heat island" effect, whereby cities tend to be hotter than surrounding rural areas. The data were also compared with maps showing residents' wealth and historically "redlined neighborhoods," where government and banks have systematically denied neighborhood development and housing loans for people of color.

This work found something striking: Yonkers' once industrial south west neighborhood, still a poorer residential area mostly home to people of color, is on average several degrees hotter than the city's leafier, whiter, more suburban areas.

Temperature differences can lead to health inequalities. Heat kills more than 600 Americans a year, according to the Centers for Disease Control and Prevention, ${ }^{1}$ and likely contributes to many more. And heat related morbidity and mortality are expected to rise, particularly among vulnerable populations. $^{2}$

The project in Yonkers was led by GroundWork, a non-profit organization founded by the National Park Service and the Environmental Protection Agency. It partnered with Vivek Shandas, a professor of urban studies and planning at Portland State University who studies the interplay between socioeconomic and racial inequalities and heat vulnerability.

Shandas was not surprised by the findings. Across the US, people of color are more likely to live in neighborhoods rich in impermeable surfaces, densely built from old, heat trapping materials like brick, and lacking trees and parks. Throughout America, poorer neighborhoods can be as much as $7^{\circ} \mathrm{C}$ warmer than wealthier neighborhoods nearby. ${ }^{3}$

Countrywide, Shandas and colleagues have shown that economically marginalized and racially segregated neighborhoods are on average $2.6^{\circ} \mathrm{C}$ hotter than non-redlined areas. ${ }^{3}$ Groups like GroundWork are using these findings to press for investment in parks and sustainable, heat ready housing in such neighborhoods.

\section{Preparing for heat}

The non-profit advocacy organization the Union of Concerned Scientists estimates that by the middle of the 21st century more than 90 million Americans will be exposed to at least 30 days a year when the temperature exceeds $40.6^{\circ} \mathrm{C}$-compared with just 900 ooo today. ${ }^{4}$ With heat waves regularly affecting cities from Phoenix, Arizona, to Washington, DC, the need to adapt to this sweltering new norm is clear, but cities' climate adaptation plans are often lacking, ${ }^{5}$ and solutions are deficient in political will and funding.

Cities have proposed various responses: warning systems that help residents to plan by stockpiling water, limiting physical activity, and using air conditioned public buildings designated as "cooling centers." 6 They've also suggested that installing drinking water fountains could reduce dehydration. Painting streets and roofs white might reduce temperatures, some cities claim. ${ }^{7}$

Cities from Los Angeles to Baltimore to New York have proposed increasing tree coverage. One of the oldest and simplest solutions to urban heat, urban planting at sufficient density can reduce temperatures. $^{89}$

The Los Angeles advocacy group Tree People, funded by the US Department of Agriculture Forest Service, claims trees could cool adjacent air by up to $5^{\circ} \mathrm{C}$ and that one in four deaths due to heat in the city might be saved with increased tree cover. ${ }^{10}$

Brigitte Griswold, who leads the GroundWork project in Yonkers, told The BMJ: "Trees can solve multiple problems. They provide shade, help increase biodiversity, absorb heat when pavement releases heat in the night time, and encourage people to be outside and do physical activity."

\section{Phoenix's grand plans}

Temperatures regularly exceed $38^{\circ} \mathrm{C}$ in Arizona's Sonoran desert, home to Phoenix, the state's largest city. With climate change and as Phoenix grows, the city is getting even hotter; this summer was the hottest on record. ${ }^{11}$ Things are expected to get worse: by 2060 the Phoenix area could have double the number of days a year over $43^{\circ} \mathrm{C}$ (there were a record 34 this year). ${ }^{12}$ 
Residents have sustained third degree burns from baking sidewalks. Arizona recorded more than 2000 heat related deaths over the 10 years from 2009 to 2019. ${ }^{13}$ Last year, Phoenix recorded 200 heat related deaths, disproportionately in hotter, poorer areas where most residents are people of color. ${ }^{14}$ Not all heat related deaths are captured in death records, so this is likely to be an undercount.

Phoenix aspires to be "heat ready" by implementing a warning system, painting streets white, shading bus stops, requiring new buildings to provide shade, and offering commuters cooled neck scarves. ${ }^{15}$ Last summer, 200 homeless people used a temporary cooling center at the city's convention center. A city-wide aim for $25 \%$ tree coverage by 2030 could return Phoenix to the "city of gardens and trees," as it was known 100 years ago, before the highways and skyscrapers. ${ }^{16}$ In 2014, the most recent data available, the city had just $13 \%$ tree cover.

But critics like Shandas argue that the city is not moving fast enough and that its fledgling, piecemeal interventions lack focus on historic inequalities. He points out that the city is not providing energy assistance to historically disadvantaged communities, even though access to air conditioning could mean the difference between life and death.

Poorer residents, such as those in Edison-Eastlake, want improvements to protect them from heat now, but planning and funding timescales can be five to 10 years. ${ }^{12}$

The city accepts that heat deaths "may be attributable to reductions in social service programs that directly or indirectly protect people from heat." ${ }^{17}$ It also recognizes that heat affects poorer residents unequally and has projects focused on improving poorer residents' homes to resist heat. Phoenix aspires to have a holistic strategy for heat by 2021, with measurable goals. Until then, uncoordinated programs get just a few years of financial support at a time.

"Heat related efforts are scattered throughout the government, and heat is sometimes only one of several goals that a particular project or policy intends to address," says David Hondula, associate professor at Arizona State University. Funding is also often split among departments and external grants.

\section{What are Phoenix and Arizona doing to tackle climate change?}

- Phoenix plans to be carbon neutral by 2050. But campaigners, including the non-profit Sierra Club, want more ambition and faster progress. It wants the city to declare a climate emergency and carbon neutrality by 2030.2223

- Despite facing extreme and perpetual drought, the city has no plan to reduce water use. It also has no plan to cap development, despite being one of the fastest growing US cities and extremely car dependent, with $60 \%$ of its carbon emissions from transportation. Also, Phoenix's nuclear power plant relies on water and may not be able to operate in extremely hot weather.

- Arizona hasn't come close to reaching a goal to reduce greenhouse gas emissions to 2000 levels by $2020 .^{24}$ Critics such as Sandy Bahr, the Phoenix chapter director for the Sierra Club, accuse the state government of underplaying the looming climate crisis and its impacts. "The city has elevated the conversation about heat related health, but the state has really done nothing," says Bahr.

- Arizona's 2017 state-wide climate and health adaptation plan mentions "climate change" only once, focusing instead on monitoring extreme

weather and educating citizens on preparation. ${ }^{25}$ Its 2018 heat response plan notes that homeless, ill, and senior citizens are more at risk from heat but does not consider how to tackle the structural inequities such as racism and income inequality that can affect vulnerability. ${ }^{26}$

\section{Dryness and heat mitigation}

Increasing dryness is also a problem. The Salt, Verde, and Colorado rivers, which supply the city, suffer from overuse and persistent drought. The Colorado river is expected to shrink by a quarter by 2050 as a result of overuse and climate change. ${ }^{18}$ Threatened water supplies put Phoenix's promise to increase tree cover at risk. About half of the city's water is already used for irrigation, with greater volumes needed when temperatures rise. ${ }^{17}$

The Sierra Club's Bahr worries that the city will miss its tree goal. "Often, when trees die or there's a storm, they're simply not replaced because there's no plan and funding for maintenance," she says. The city admits that trees have been lost faster than it can replace them, its tree budget much lower than in other US cities. ${ }^{19}$

Phoenix's chief sustainability officer, Mark Hartman, says that heat mitigation efforts have been "almost exclusively focused on vulnerable communities." He maintains that Phoenix is marching toward its "urban forest" goal, spending over \$5m (£3.9m; €4.3m) to plant 4000 trees a year, with a new focus on low income areas that need cooling the most.

\section{Cities putting ambition into action}

Some cities around the world have put plans into action, with more comprehensive, longer term approaches. Singapore launched its Landscaping for Urban Spaces and High Rises policy in 2009. This requires all new building developments to include planting of the same footprint. With planting on rooftops, the sides of high rise buildings, and apartment balconies, the city is becoming greener.

Singapore's centralized government might explain its leadership in urban climate preparedness, Shandas says. But other cities are catching up. Arnhem, in the Netherlands, is removing $10 \%$ of its asphalt surfaces and adopting "cooling down” spots-with ponds and covered areas-near busy neighborhoods. These actions are alongside ambitious national goals to reduce greenhouse gas emissions to $95 \%$ of 1990 levels by 2050 to try to slow climate change.

Some US cities have ambition too. Ordinances in Los Angeles require tree planting, and all new public and private buildings must have reflective roofs, with a goal to reduce the average difference between urban and rural temperatures by $1.7^{\circ} \mathrm{C}$ by $2035 .{ }^{20}$ Austin has suspended electricity shut-offs for poorer residents so they can keep air conditioning on. ${ }^{21}$

The US Union of Concerned Scientists advocates for a comprehensive, national approach, with minimum cooling standards in public housing and funding for cooling strategies, alongside ambitious cuts to carbon emissions (the US currently has no emissions reduction plan). ${ }^{6}$

Shandas supports coordinated government intervention countrywide, including energy assistance programs for poorer households and tax breaks to encourage new homes to use heat resistant building materials and roofs.

In the meantime, cities like Yonkers are taking small steps. After consulting with GroundWork, Shandas, and residents, the city is hoping to increase tree cover and offer solar power to low income residents. Empirical data are vital for making the case for investment, says Wilson Kimball, president and chief executive of the city's municipal housing. But funding is yet to be found.

Fledgling, pragmatic initiatives still count, Shandas emphasizes. "It's saying, 'Now that we have to maintain our roof, let's paint it 
white. Now that we have to establish a cooling center, let's plant trees outside."”

But what he finds exciting is that policy makers like Kimball are paying attention to the interplay between heat and inequality. "How do we get systems that have created inequities to prioritize disinvested communities?" he asks.

Tackling the disproportionate impact of heat and dryness on poorer neighborhoods offers opportunities to improve people's lives in other ways. GroundWork's Griswold says, "You can't solve the problem without looking at public health, environmental health, racism, and poverty."

Competing interests: I have read and understood BMJ policy on declaration of interests and have no relevant interests to declare.

Provenance and peer review: Commissioned; not externally peer reviewed.

This article is part of a series commissioned by The BMJ for the World Innovation Summit for Health (WISH) 2020. The BMJ peer reviewed, edited, and made the decision to publish. The series, including open access fees, is funded by WISH.

1 Centers for Disease Prevention and Control. Extreme heat. 2019. https://www.cdc.gov/disasters/extremeheat/index.html

2 Sampson NR, Gronlund CJ, Buxton MA, etal. Staying cool in a changing climate: reaching vulnerable populations during heat events. Glob Environ Change 2013;23:475-84 doi: 10.1016/j.gloenvcha.2012.12.011 pmid: 29375195

3 Hoffman JS, Shandas V, Pendleton N. The effects of historical housing policies on resident exposure to intra-urban heat: a study of 108 US urban areas. Climate (Basel) 2020;8:12doi: 10.3390/cli8010012

4 Dahl K, Spanger SE, Licker R, et al. Killer heat in the United States: climate choices and the future of dangerously hot days. Union of Concerned Scientists. 2019. https://www.ucsusa.org/sites/default/files/attach/2019/07/killer-heat-analysis-full-report.pdf

5 Keith L, Meerow S, Wagner T. Planning for extreme heat: a review. J Extreme Events 2020;6:2050003. doi: 10.1142/S2345737620500037.

$6 \quad$ New York City. Frequently asked questions about cooling centers. 2020. https://www.health.ny.gov/environmental/weather/cooling/ccfaq.htm

7 NYC Business. NYC CoolRoofs. 2020. https://www1.nyc.gov/nycbusiness/article/nyc-coolroofs

8 Bowler DE, Buyung-Ali L, Knight TM, Pullin AS. Urban greening to cool towns and cities: A systematic review of the empirical evidence. Landsc Urban Plan 2010;97:147-55. doi: 10.1016/j.landurbplan.2010.05.006.

9 Ziter CD, Pedersen EJ, Kucharik CJ, Turner MG. Scale-dependent interactions between tree canopy cover and impervious surfaces reduce daytime urban heat during summer. Proc Natl Acad Sci U S A 2019;116:7575-80. doi: 10.1073/pnas.1817561116 pmid: 30910972

10 de Guzman E. RX for hot cities: climate resilience through urban greening and cooling in Los Angeles. Tree People. 2020. https://www.treepeople.org/sites/default/files/pdf/publications/RXfor-hot-cities-report.pdf

11 Maricopa County Public Health. Heat associated deaths and hospital visits 2020 weekly report. Week 38 (09/13-09/19). https://www.maricopa.gov/ArchiveCenter/ViewFile/Item/5102

12 Heat Action Planning Guide. Edison-Eastlake Community. https://repository.asu.edu/attachments/220970/content/HeatActionPlan_EdisonEastlake_highRes.pdf

13 Arizona Department of Health Services. Heat-caused and heat-related deaths in Arizona by year (2009-2019). https://www.azdhs.gov/documents/preparedness/epidemiology-disease-control/extreme-weather/pubs/heat-related-mortality-in-arizona-by-year-2009-2019.pdf

14 Maricopa County Public Health. Heat-associated deaths in Maricopa County, AZ. 2019. https://www.maricopa.gov/ArchiveCenter/ViewFile/Item/4959

15 Bloomberg Philanthropies. Mayors challenge. Phoenix, AZ: 2018 Champion City. 2020. https://mayorschallenge.bloomberg.org/ideas/phoenix/

16 City of Phoenix. Parks and recreation. Learn about Phoenix’s urban forest. 2020 https://www.phoenix.gov/parks/parks/urban-forest/tree-and-shade

17 City of Phoenix. Attachment A: Creating a cooler Phoenix. strategy to address urban heat. 2019. https://apps-secure.phoenix.gov/PublicRecordsSearch/Home/RenderPDF/?id=xv4vmLvnVEM4nXmuQ97pbDOugny2sJjAV/bpJEVfDCo=

18 Milly PCD, Dunne KA. Colorado river flow dwindles as warming-driven loss of reflective snow energizes evaporation. Science2020;367:1252-5. doi: 10.1126/science.aay9187 pmid: 32079679

19 City of Phoenix. Tree and shade master plan. 2010. https://www.phoenix.gov/parkssite/Documents/PKS_Forestry/PKS_Forestry_Tree_and_Shade_Master_Plan.pdf

20 Garcetti E. LA's green new deal: sustainable city plan 2019.2019. https://plan.lamayor.org/sites/default/files/pLAn_2019_final.pdf

21 Rock J, August H. Killer heat: US cities' plans for coming heatwaves fail to protect vulnerable. Guardian 2019 Dec 6. https://www.theguardian.com/cities/2019/dec/06/killer-heat-us-citiesplans-for-coming-heatwaves-fail-to-protect-vulnerable
22 City of Phoenix. Environmental sustainability goals. 2020 https://www.phoenix.gov/sustainability/energy

23 Georgetown Climate Center. Overview of Arizona's climate change preparations. 2020. https://www.georgetownclimate.org/adaptation/state-information/arizona/overview.html

24 City of Phoenix. Climate action plan for government operations. 2009 https://www.phoenix.gov/oepsite/Documents/d_026991.pdf

25 Roach M, Barrett E, Brown HE, et al. Arizona's climate and health adaptation plan. 2017. https://www.azdhs.gov/documents/preparedness/epidemiology-disease-control/extremeweather/pubs/arizona-climate-health-adaptation-plan.pdf

26 Arizona Department of Health Services. Addendum to the Arizona climate and health adaptation plan. 2018. https://azdhs.gov/documents/preparedness/epidemiology-disease-control/extremeweather/pubs/addendum-to-az-climate-health-adapt-plan.pdf

This is an Open Access article distributed in accordance with the Creative Commons Attribution Non Commercial (CC BY-NC 4.0) license, which permits others to distribute, remix, adapt, build upon this work non-commercially, and license their derivative works on different terms, provided the original work is properly cited and the use is non-commercial. See: http://creativecommons.org/licenses/by$\mathrm{nc} / 4.0 /$. 